\title{
Commentary: The status of theoretical divisions in current semiotics
}

Claudio J Rodríguez Higuera

Department of General Linguistics, Palacký University in Olomouc, Czech Republic

Received: August 2021; Accepted: September 2021

\begin{abstract}
We initiate a new section of the journal, an invited commentary on issues pertaining to the fields of semiotics and linguistics and personal views on what is happening in the field. In this introduction, we assess the current status of the divisions of semiotics into multiple branches and the historical overview of the semiotics/semiology debate.
\end{abstract}

Keywords: commentary; metatheory; semiotics and linguistics; branches of semiotics; semiology

Linguistic Frontiers emerged as a project to build a platform for new ways of doing linguistics and semiotics. Incorporating Biosemiotics as a core conceptual element in our editorial line, we have tried to articulate our vision through ways of looking at current semiotic trends that may at times appear more experimental, or at least more interested in the coming together of ideas from the interaction of linguistic methodologies and perspectives from philosophy.

One of the more ambitious aims of the journal has been establishing its presence as a wider-scale theoretical setting for research on the borders of semiotics and its conjoining fields, whatever those may be. We want to open thus a new section in our journal in the form of an invited commentary, a space where both established and upcoming voices can bring their opinions to the forefront on disciplinary issues, theoretical perspectives and grounded speculation on the borders of the disciplines we cover in the journal. By doing this we believe authors can have an added degree of freedom for contributions that may not always find a home within the current production of research articles. These commentaries will serve as a bridge for new ideas brewing and open opinions that can, or so is our hope, expand the frontiers of linguistic and semiotic research.
In this first exploration, the topic I would like to bring to the forefront is metatheoretical in its conception. Semiotics as a whole is an edifice comprised of multiple branches, some of them connected only nominally, it would seem. We have a core number of assumptions made by the concept of semiotics, namely, for instance, that signs matter, but what matters in terms of signs is a much different story. What I mean to ask-though I'm afraid there won't be a satisfying answer-is what connects these divisions in both theory and practice.

The semiology/semiotics distinction is one that, as a whole, has lost currency over the last decades, particularly among researchers publishing in English. Permeated by the historiography of the discipline, it would seem that, mirroring the situation in philosophy during the 20th century, the division was formal and qualitative at the same time. That is, to speak of semiotics in the context of its difference with semiology means, to some extent, qualifying the disciplines as diverging conceptually-the linguistic implications of semiology vs. the assumed allegiance of semiotics with Peircean philosophy.

Both of these areas are most likely less loosely defined than this story would tell us though. Say, it is easy to establish the "continentality" of semiology, particularly when observing the historical development across the French-speaking areas of Europe ${ }^{1}$. However, the existence

1 Deely (2009) reminds us of Georges Mounin's dislike for the concept of "sémiotique" as applied to "sémiologie" 


\section{Rodríguez}

of multiple schools of thought, of Danish and Soviet strands, makes the claim much less certain, and not based on stylistics.

The world of semiotics is not that large, in any case. Soviet semioticians were keenly aware of the different lines of semiotic thought. The old Polish school of semiotics-an oddity if we may say so across the European landscape-and its current remnants are still very much a distinct, philosophically analytical trend in semiotics in general.

The consolidation of concepts did not, however, mean a true consolidation of theory, and that is, we could presume, a positive development, in that there is no limiting of frameworks we can use for the work we do in semiotics. The true question lies in knowing whether there is any conceptual unity at all when we do semiotics, and whatever that actually means.

In order to assess what the panorama looks like in terms of current divisions of semiotics, we first need to assess what it means to do semiotics then, and this is not a question to tackle easily. There are multiple nominal branches of semiotics, from the more institutionally organized ones such as biosemiotics, to the more idiolectal ones, such as existential semiotics, or the more programmatic ones, such as experimental semiotics or cybersemiotics, to name a few. What is the common denominator in all of these (besides their shared moniker)? Often, there is relevant overlap in theoretical commitments, such as the usage of some or many Peircean concepts, but in the world of formal research, this may not be enough to grant their belonging to the group of semiotics, at least in the sense that one may have certain theoretical commitments to a specific philosophical perspective without calling oneself something based on these commitments.

Across multiple introductions to semiotics, we find statements such as how semiotics deals with meaning-making, signs or sign-systems (Salupere and Kull 2018: 19), or how semiotics, within a philosophical orientation, trades in the recognition of ideas as representational, broadly speaking² (Deely 2009: 13), or the fact that semiotics aims to study "everything that can be taken to be a sign" (Eco 1976: 7), or even that semiotics is the science that studies the specific kinds of signs of a given species, their production, usage and reception (Sebeok 2001: 3).
We can also trace back some semiological principles when Barthes states that "working at the outset on nonlinguistic substances, semiology is required, sooner or later, to find language (in the ordinary sense of the term) in its path, not only as a model, but also as component, relay or signified" (1964: 10-11). If semiology, widely construed here as based on at least similar principles as those just mentioned, imprints on us the need to find structure in signifying systems, and if the consolidation of terminology implied the subsuming of semiology into a wider concept of semiotics, there may be something interesting to take from this mix of perspectives, namely, that signification is at the heart of any semiotics.

The next question we face is what we actually mean by signification, particularly when we have moved our position away from a more traditional semantics of language. Even more broadly, we have the concept of meaning as the ideological cornerstone of semiotics, so to speak ${ }^{3}$. If these concepts, as well as that of semiosis, are to be understood both separately and as having technical nuance, then it is perhaps in how we define these concepts that we can find the point of communion between the different varieties of semiotics. How tightly are these concepts defined though? The qualitative considerations behind them may prevent a direct, constant and replicable application of the terms, but in an effort to provide a minimal hint of unity, we can say that these all have a specific usage. If meaning is not signification is not semiosis, then a case must be made about their conceptual differences, even if we are not able to make these as fine-grained as we would like. Take, for instance, signification. In his A Theory of Semiotics, Eco defines it as a rule-based standing-for relation (1979: 8). For a Lotmanian definition of signification, however, we depend on a layer of interpretive action. Godzich, for instance, tells us that for Lotman, signification takes place when "two structural concatenations of differential elements are cojoined and an operation of "transcoding" occurs" (1978: 391). Formal elements (expression) become paired with conceptual elements (content). These two different descriptions of signification are certainly not incompatible prima facie, as both point out to the conventional nature of signification. But both positions make different assumptions about what matters in conventionality ${ }^{4}$.

(1970) during a crucial stage of this distinction. Mounin sees Charles Morris's concept-borrowed from Peirce-as outdated, a curiosity of the history of the discipline (57), and a "behavioral linguistics", not a kind of semiology (66), the latter an encompassing concept that should not necessitate invoking a "sémiotique" to designate semiology in general. 2 This is certainly a very reductive view of Deely's perspective, but the point that stands is that Deely's introduction to what semiotics is and does depends on the perspective that signs and the activity through which we come to know them are distinctive enough to be studied on their own, and that what we have access to, epistemologically speaking, is indeed part of the world of signs.

3 I do not hope to impress on the reader a strong character of the concept of ideology here. Instead, I refer to meaning as such because it seems to be the central concern of semiotics, though how we define it and to what degree we stick to that definition is something of a conflict.

4 Godzich takes it a step further by stating that Lotman's notion of signification reverses signified and signifier and conflates denotation with connotation (391). The correctness of this assumption, however, is left for the 
What is meaning for semiotics then? If signification is the process of codes matching for some perceiver, and if we assume that as a technical term it does not overlap completely with meaning, then the latter has to show conceptual difference and usefulness for the theory. Meaning is much harder to tame in semiotics than it is in linguistics because of the wider variety of phenomena attached to the notion of semiotics itself. In the wider sense conveyed by semiotics, meaning can be construed around different theories. Within a Peircean framework, Houser hints at meaning as the determination of an interpretant for a previous object (2014: $13)^{5}$. One issue we run into here is distinguishing sense from meaning altogether, and so begins a problem of meaning as a technical term for semiotics altogether. The point of a technical concept of meaning is in being able to provide theoretical approaches to how we either discover or deal with said meaning. A theory of reference may not actually do enough for us to consider it a theory of meaning, and so this disaffection from the linguistic form carries a burden of its own: That its sense of meaning must satisfactorily yield some result. If meaning as more than loose parlance is to be relevant for semiotic theories, then it must mean something.

Finally, the elusive concept of semiosis, often characterized as "the action of signs", may be defined in more or less technical terms as "a continuous process that is based on the interpretation of one sign through another" (Krampen et al. 1987: 244, cited in Kull 2002: 329)6. Yet, how informative is it as a core concept? Even for a Peircean semiotic theory, does it carry any actual weight beyond being a shortcut of something akin to "a chain of Peircean signs"?

With all of these terminological issues at hand, what is at the core of semiotic theories that allows us to talk about them as semiotic theories? There is little in the way of technical coherence, but there is, most likely, a shared vocabulary, though the degree of compatibility across usages is a relevant crease across our landscape. Is it perhaps possible that the historical ramifications of the semiology/semiotics distinction are what lies behind this disparity in conceptual technology? This, we can suppose, is a question better posed to future historiographers of the discipline.

One answer, and perhaps the least satisfactory one of all, is that semiotics is, as Deely poised, a "point of view". And the complaint is not about the differentiation between methodology and point of view, as it was the issue between semiology and semiotics as expressed during the time of Deely's seminal Basics of Semiotics. Instead, the problem here lies in that semiotics as a point of view is a loosely defined holistic paradigmatic perspective on the sciences and the humanities. Akin to a moral stance, what accompanies semiotics is usually the desire to find the meaning, structural or otherwise, of things. Now, as vague as this sounds, the idea is that across the different varieties of semiotics the main unifying trend is not always terminological, but rather, it is a general stance about things that have value in their exploitation, intellectually speaking. The separation across the naturalized semiotics and the more traditional ones can be characterized with the former as allowing meaning-like properties to provide causal explanations of some sort, and the latter as providing analyses of present elements and relationally absent elements within a particular object of study. So say, branches like biosemiotics will offer explanations of biological phenomena appended to semiotic terminology or referring to specific semiotic devices or mechanisms (however we construe those) as crucial for understanding said biological phenomena, like for instance in the construction of a theory of semiotic scaffolding as a form of control and causation of biological processes tied to survival (Hoffmeyer 2007). On the other hand, the semiotics of cinema will more often than not refer to textual relations, semiotic representation or the structure of the medium (as in Eagle 1976), a decidedly different dimension of analysis as that of a more naturalized program such as cybersemiotics, for instance, where we may want to explain informational talk through first-person experience as a way to cover the gap from matter to mind (Brier 2008).

The problem of semiology vs. semiotics has been solved institutionally, but conceptually there are large gaps in theories that make the current status of the field and its separations far more corrugated than one would expect at first sight.

What this presupposes for semiotics as a whole is that the grand theories, such as Peircean philosophy, may contribute to a shared language, but they do not provide us with an ultimate theory of semiotics. This is positive to a very large degree because a solved theory is a dead theory. However, the variety of explanations and needs points to a more symbolic form of union, and not one based on theoretical premises. It is hard to assess

\footnotetext{
reader to decide.

5 Regrettably, this particular expression comes as paired with signification, muddling any potential distinction from this perspective. The more permeated a terminology becomes by a specific theoretical allegiance, the harder it may be to find theoretical correlates to a more common parlance in what we call general semiotics. There is, of course, much nuance to the concepts brought from Peirce, and it deserves more attention than we can give it in the current space.

6 Making the picture more complex, we find definitions such as "an irreducible triadic relation between a Sign, its Object (the object, act or event with which it inter-relates) and its Interpretant (that which is becoming interpreted through its inter-action with its interpreter)" (Queiroz and Merrell 2006: 40), making it hard to differentiate from the Peircean sign relation and thus, making both concepts overlap, despite their nominal difference.
} 


\section{Rodríguez}

whether this is a positive development though, and it would be presumptuous to say it is or isn't. Instead, what we have at hand is akin to what is meant by things like philosophy, and deserving of much more direct questioning. What is the status of semiotics? What is semiotics, as far as research programs go? Being historiographically part of a philosophical tradition makes the current situation of the field cloudy for the backwoodspeople working on it, but the development of these questions can have actual, unforeseen ramifications for all of the field, future, present and past.

\section{REFERENCES}

Barthes, R. (1997). Elements of Semiology. Hill \& Wang. Brier, S. (2008). Cybersemiotics: Why Information is Not Enough! University of Toronto Press.

Deely, J. N. (2009). Basics of Semiotics (5 $5^{\text {th }}$ ed.). University of Tartu Press.

Eagle, H. (1976). The semiotics of cinema: Lotman and Metz. Dispositio, 1(3), 303-313.

Eco, U. (1976). A Theory of Semiotics. Indiana University Press.

Godzich, W. (1978). The Construction of Meaning.
New Literary History, 9(2), 389-397. https://doi. org/10.2307/468581

Hoffmeyer, J. (2007). Semiotic Scaffolding of Living Systems. In M. Barbieri (Ed.), Introduction to Biosemiotics: The New Biological Synthesis (pp. 149-166). Springer Netherlands. https://doi.org/10.1007/1-4020-4814-9_6

Houser, N. (2014). The Intelligible Universe. In V. Romanini \& E. Fernández (Eds.), Peirce and Biosemiotics: A Guess at the Riddle of Life (Vol. 11, pp. 9-32). Springer.

Krampen, M., Oehler, K., Posner, R., Sebeok, T. A., \& Uexküll, T. von. (1987). Classics of Semiotics. Plenum Press.

Kull, K. (2002). A Sign Is Not Alive-A Text Is. Sign Systems Studies, 30(1), 327-336.

Mounin, G. (1970). Introduction à la sémiologie. Éditions de Minuit.

Queiroz, J., \& Merrell, F. (2006). Semiosis and pragmatism: Toward a dynamic concept of meaning. Sign Systems Studies, 34(1), 37--65.

Salupere, S., \& Kull, K. (Eds.). (2018). Semiootika. Tartu University Press.

Sebeok, T. A. (2001). Signs: An introduction to semiotics $\left(2^{\text {nd }} \mathrm{ed}\right.$.). University of Toronto Press. 